\title{
Marketing Politik Pemilukada Cagub Provinsi Bengkulu Tahun 2020 (Studi Pada Pasangan Helmi - Dedi)
}

\author{
Novliza Eka Patrisia ${ }^{a, 1, *}$, Hafri Yuliani ${ }^{b, 2}$ \\ 1,2 Prodi Administrasi Publik, FISIP UnMuh Bengkulu, Indonesia \\ ${ }^{1}$ Email : ${ }^{1}$ novlizaekap@umb.ac.id \\ * corresponding author
}

\section{ARTICLE INFO}

Article history

Received 2020-11-18

Revised 2020-12-22

Accepted 2020-12-30

Keywords

Political Marketing:

push political marketing,

pull political marketing;

political marketing pass;

Pemilukada.

\begin{abstract}
This paper is a result of the analysis and observations that the researchers conducted directly and openly. This research was carried out continuously by looking at several aspects related to the promotion of candidates as participants in the 2020 Bengkulu Provincial Election for Cagub. In this case the researchers focused on political marketing used by the number 1 pair, Helmi-Dedi. The research method used is the constructivist paradigm. Based on the results of research on political marketing applied by candidate pairs Helmi -Dedy in the Regional Head Election for the 2018-2023 period using an analysis knife, namely the Political Marketing Theory of Adnan Nursal (Nursal, 2004: 242) has three target groups that can be grouped into three: 1. Direct marketing of political products to potential voters (push political marketing), 2. Marketing of political products through mass media (pull political marketing) and 3. through influential groups, figures or organizations (pass political marketing).
\end{abstract}

\section{PENDAHULUAN}

Sistem demokrasi di Indonesia telah mengantarkan masyarakat untuk bisa memilih dan dipilih dalam pemilihan umum. Indonesia adalah negara yang menganut sistem pemerintahan demokrasi. Demokrasi adalah suatu bentuk pemerintahan yang kekuasaan pemerintahannya berasal dari rakyat, oleh rakyat, untuk rakyat. Pemilihan umum telah mengantarkan seseorang untuk mengisi jabatan politik tertentu. Jabatan tersebut mulai dari jabatan presiden/eksekutif, wakil rakyat/legislatif di berbagai tingkat pemerintahan, sampai kepala desa.

Dalam memenangkan hati rakyat banyak hal yang dilakukan oleh calon legislatif maupun eksekutif dalam mempublikasikan dirinya. Marketing politik yang di lakukan calon seperti memasang spandukspanduk di pinggir jalan, memasang bildboard di jalan-jalan utama. Tidak hanya itu , pendekatan yang dilakukan kepada tokoh politik, tokoh agama, tokoh pemuda serta organisasi-organisasi pemuda. Selain itu banyak calon legislatif yang lagsung turun kepalangan, dengan mendatangi pesta-pesta serta memberikan bantuan sebagai bentuk promosi diri sehingga masyarakat bisa tahu dan bisa menentukan pilihan. Political marketing merupakan serangkaian aktivitas terencana, strategis dan taktis, dimensi jangka panjang dan pendek. Serta menekankan pada penggunaan pendekatan dan metode marketing untuk membantu politikus ataupun partai politik agar lebih efisien serta efektif dalam membangun hubungan dua arah dengan konstituen dan masyarakat. (Nursal ,2004).

Setiap kandidat politik dapat menyampaikan produk politik secara langsung kepada khalayak sasaran. Kandidat calon legislatif dapat menyampaikan produk politik kepada khalayak sasaran dengan cara publikasi yang dilakukan secara langsung tetapi juga menggunakan tokoh agama, tokoh pemuda, tokoh masyarakat, tokoh politik yang berpengaruh besar kepada khalayak sasaran, selain itu yang tidak kalah penting bahkan bisa dikatan menjadi point penting di zaman sekarang yaitu penggunaan media massa. Penggunaan media massa telah mempermudah setiap kandiddat untuk di kenal sampai kepelosok daerah. Penggunaan media massa telah mempermudah kandidat memberitahu rekam jejak perjalanan politik setiap kandidat. Dengan pemberitaan melalui televisi telah memberitahu khalayak sasaran tentang visi misi kandidat.

Dalam kompetisi politik Strategi politik sangat dibutuhkan, strategi komunikasi politik selain sebagai penentu kemenangan politik kompetitor, strategi komunikasi politik juga dapat mempengaruhi 
perolehan pada suara suatu partai politik. Strategi komunikasi politik dapat memberikan manfaat dalam membangun dan menciptakan kekuatan melalui kontinuitas juga konsistensi. Hal ini dapat dilakukan dalam kegiatan taktiknya dalam berpolitik melalui komunikasi. Perencanaan taktis dapat berjalan lebih mudah dan cepat, ketika strategi jelas arahnya dan disepakati bersama. Effendi (1993) berpendapat bahwa untuk mencapai tujuan strategi komunikasi politik, strategi tidak akan berfungsi sebagai peta jalan yang hanya menunjukkan arah saja, melainkan harus mampu menunjukkan bagaimana taktik operasionalnya. Observasi dilapangan, peneliti mengamati penerapan marketing politik yang diterapkan oleh Kandidat Pasangan no urut 3 Pasangan Helmi Hassan dan Dedy Wahyudi dalam memenangkan Pemilihan Umum Kepala Daerah Kota Bengkulu Periode 2018-2023. Dari latar belakang diatas menarik untuk di teliti lebih dalam mengenai marketing politik yang diterapkan dalam pemiluhan umum kepala daerah Kota Bengkulu yang diterapkan oleh Helmi Hassan dan Dedy Wahyudi.

\section{LANDASAN TEORI}

\section{Marketing politik}

Menurut Firmanzah (2012: 156), marketing politik bukanlah konsep untuk menjual partai politik atau kandidat individu ke pemilih, namun sebuah konsep yang menawarkan bagaimana sebuah partai politik atau kandidat individu bisa membuat program yang berhubungan dengan permasalahan aktual.

Pendekatan marketing dalam dunia politik dikenal dengan marketing politik (political marketing). Dalam marketing politik, yang ditekankan adalah penggunaan pendekatan marketing untuk membantu kandidat dan partai politik agar lebih efisien dan efektif dalam membangun hubungan dua arah dengan konstituen dan masyarakat. Hubungan ini diartikan sangat luas, dari kontak fisik selama periode kampanye sampai dengan komunikasi tidak langsung melalui pemberitaan di media massa (Firmanzah, 2012:128).

Konsep marketing politik mencoba untuk melakukan perubahan-perubahan didalam dunia politik dengan tujuan agar dapat mengembalikan dunia politik kepada tujuan semula yaitu menyerap dan mengapresiasikan pendapat masyarakat. Perubahan-perubahan tersebut diantaranya (dikutip dari O'Cass dalam Firmanzah 2012: 156) adalah

1. Menjadikan pemilih sebagai subjek, bukan objek dari para kandidat. Menjadi subjek berarti bebas menentukan pilihan sendiri tanpa adanya tekanan dari apapun dan manapun. Subjek menentukan mana yang terbaik bagi dirinya sendiri dan bukannya ditentukan oleh pihak lain atau orang lain. Sedangkan menjadi objek berarti tidak dapat menentukan pilihan mereka sendiri.

2. Menjadikan permasalahan yang dihadapi pemilih sebagai langkah awal dalam menyusun program kerja yang ditawarkan sebagai pemecahan masalah.

3. Marketing politik tidak menjamin sebuah kemenangan, tetapi menyediakan tools untuk menjaga hubungan dengan pemilih sehingga dari situ akan terbangun kepercayaan, sehingga selanjutnya akan diperoleh dukungan suara mereka.

Penjelasan mengenai marketing politik diatas dapat disimpulkan bahwa marketing politik merupakan sebuah konsep mengenai langkah yang digunakan untuk memenangkan kompetisi dalam pemilihan umum dengan cara dan taktik yang mampu mempengaruhi dan membuat pilihan khalayak jatuh ke kandidat yang di promosikan.

\section{Teori Push, Pull dan Pass Political Marketing}

Menurut Philip Kotler (dalam firmanzah, 2008:217) dalam Marketing Politik, terdapat 4 P yaitu (Produk, Place, Price, Promotion). Dari 4 P yang dikemukakan oleh Philip Kotler, Adnan Nursal mengembangkan kembali dari Promosi menjadi 3 (tiga) point yitu Push, Pull, Pass Political Marketing . Adapun penjelasan secara rinci teori Push, Pull dan Pass Political marketing yaitu : 1. Pemasaran produk politik secara langsung kepada calon pemilih (push political marketing ), 2. Pemasaran produk politik melalui media massa (pull political marketing) dan 3. melalui kelompok, tokoh atau organisasi yang berpengaruh (pass political marketing). Masing-masing akan dijelaskan di bawah ini :

1) Pemasaran Langsung Kepada Calon Pemilih (Push Political Marketing) 
Push Political Marketing merupakan pemasaran produk politik secara langsung ke calon pemilih. Strategi ini lebih berfokus pada isu-isu yang penting bagi para electorate dan bukan hanya menjual kandidat atau partai sebagai sebuah komunitas. Pesan komunikasi pada strategi ini bisa disampaikan secara langsung oleh kandidat atau partai, tapi bisa juga melalui relawan yang datang membagikan brosur, flyer, sticker dan sebagainya. Relawan inilah yang bertugas untuk mengumpulkan data yang berupa persepsi electorate, mengukur pengaruh pesan dan mencatat perubahan dalam sikap dan perilaku electorate. Dalam pemilihan tingkat nasional, strategi ini adalah hal yang paling sulit dilakukan mengingat membutuhkan banyak tenaga dan biaya. Namun untuk pemilihan lokal cara ini cukup mudah untuk dilakukan.

\section{2) Pemasaran Melalui Media Massa (Pull Political Marketing)}

Pull Political Marketing adalah strategi yang paling banyak digunakan oleh partai dan kandidat. Penyampaian pesan strategi ini dilakukan melalui media massa baik elektronik, cetak, luar ruang, mobile dan internet. Strategi ini mempunyai kelebihan dapat membombardir pesan kepada khalayak, namun kurang dapat terukur efektivitasnya. Karena membutuhkan biaya yang sangat besar, strategi ini biasanya dilakukan oleh partai atau kandidat kaya atau mempunyai dana kampanye yang banyak.

3) Pemasaran Malalui Tokoh, Kelompok atau Organisasi Berpengaruh (Pass Political Marketing)

Strategi yang terakhir adalah pass political marketing, strategi ini penyampaian pesan dilakukan melalui individu, kelompok atau organisasi yang mempunyai pengaruh. Strategi ini memerlukan kehati-hatian dalam melakukannya karena jika terjadi kesalahan maka akan berakibat fatal (pesan komunikasi tidak akan diterima ) bahkan ditolak. Cara-cara pendekatan dan lobbying pada strategi ini perlu disesuaikan dengan tipe-tipe individu, kelompok dan organisasinya. Tidak bisa satu "transaksi" digunakan untuk semua.

\section{METODE}

Penelitian ini menggunakan paradigma konstruktivis. Paradigma konstruktivis tidak terlepas dari pengamatan dan menganggap kenyataan itu hanya bisa dipahami dari pengalaman. Paradigma ini mengkonstruksi perilaku manusia dalam realitas sosial baik melalui pemberian makna atau pemahaman perilaku.

Penelitian ini mengkaji dan menggambarkan Marketing politik dalam Pemilihan Kepala Daerah. Penelitian ini menggunakan teori marketing politik dari Philip Kotler (dalam firmanzah, 2008:217) dalam Marketing Politik, terdapat 4 P yaitu ( Produk, Place, Price, Promotion). Dari 4 P yang dikemukakan oleh Philip Kotler ,peneliti melihat dari point Promosi yang dikembangkan oleh Adman Nursal (2004:242) terdiri dari tiga strategi yaitu : 1. Pemasaran produk politik secara langsung kepada calon pemilih (push political marketing ), 2. Pemasaran produk politik melalui media massa (pull political marketing) dan 3 . Pemasaran Produk melalui kelompok, tokoh atau organisasi yang berpengaruh (pass political marketing).

\section{HASIL DAN PEMBAHASAN}

Berdasarkan Hasil Penelitian mengenai marketing politik yang diterapkan oleh pasangan kandidat Pasangan Helmi Hassan Dan Dedy Wahyudi dalam Pemilihan Kepala Daerah untuk periode 2018-2023 dengan menggunakaan pisau analisis yaitu Teori Marketing politik dari Adnan Nursal (Nursal, 2004: 242) memiliki tiga kelompok sasaran yang dapat dikelompokkan mejadi tiga : 1. Pemasaran produk politik secara langsung kepada calon pemilih (push political marketing ), 2. Pemasaran produk politik melalui media massa (pull political marketing) dan 3. melalui kelompok, tokoh atau organisasi yang berpengaruh (pass political marketing).

Berdasarkan hasil penelitian mengenai pemasaran produk politik secara langsung kepada calon pemilih atau disebut dengan Push political marketing. Dilakukan secara langsung baik dengan mengadakan event-event khusus seperti rapat umum, pawai, kontes, seminar, konfrensi dan sebagainya. Selain itu juga melalui beberapa kegiatan berskala kecil seperti pembicaraan personal, lobi politik, persentasi terbatas, pertemuan terbatas dan seminar. Hasil penelitian yang peneliti lakukan, pasangan calon nomor urut 3 Helmi Hassan dan Dedy Wahyudi melakukan pemasaran produk politik secara 
langsung yaitu dengan cara seminar dan sosialisasi dengan mengundang khalayak sasaran dan mendatangkan pakar atau ahli ekonomi, ahli politik serta mengupas program yang akan diaktualisasikan apakah pas dan tepat dari segi ekonomi maupun dari segi politik. Selain itu pemasaran secara langsung dilakukan dengan cara datang langsung sebagai tamu undangan pada saat pesta - pesta yang di adakan oleh khalayak. Hal kecil seperti ini, mampu memupuk kedekatan secara emosional antara kandidat dan khalayak, Karena ketika sudah ada komunikasi dua arah antara kandidat dan khalayak sasaran sedikit banyak akan mempengaruhi khalayak dalam menentukan pilihan. Selain itu menjadi pembicara dalam berbagai kegiatan, menjadi narasumber pada saat seminar dilakukan oleh pasangan no urut 3. Sehingga dari interaksi pada saat seminar berdampak pada citra positif yang terbangun di khalayak sasaran. Dari kegiatan secara langsung yang dilakukan oleh pasangan no urut 3 memberikan dampak yang luar biasa mampu memberikan nuansa berbeda, karena mampu masuk diberbagai lini dan berujung pada citra positif yang melekat pada pasangan nomor urut 3 .

Berdasarkan hasil penelitian dari segi Pull Political Marketing adalah strategi yang paling banyak digunakan oleh partai dan kandidat. Penyampaian pesan strategi ini dilakukan melalui media massa baik elektronik, cetak, luar ruang, mobile dan internet. Strategi ini mempunyai kelebihan dapat membombardir pesan kepada khalayak. Pasangan no urut 3 yaitu Helmi Hasan dan Dedy Wahyudi sangat diuntungkan ,Pertama Helmi Hasan merupakan kandidat yang sebelumnya menjadi Wali Kota Bengkulu (Incumbent), Kedua Dedy Wahyudi merupakan mantan General manajer dari salah satu TV lokal di Provinsi Bengkulu yaitu RB TV. Sehingga dari segi pemberitaan ada beberapa Program RB TV yang menayangkan program pemerintah Kota Bengkulusejak Tahun 2012 seperti pembangunan jalan di kota Bengkulu, Jalan-jalan mulus di kota Bengkulu, program ini telah mampu membuat masyarakat kota Bengkulu merasakan dampak program yang di implementasikan Helmi Hasan dan Patrian Sosialinda. Dari program yang telah terealisasi, memberikan sebuah nilai plus di khalayak sasaran bahwa apa yang di canangkan dan menjadi program telah di implementasikan dan menjadi sebuah prestasi. Selain itu setiap program pemerintah Kota Bengkulu selalu di siarkan oleh RB TV, sehingga semua pemberitaan yang positif oleh media lokal mengenai kepemimpinan Helmi Hassan dengan mengemas prestasi yang telah di implementasikan memberikan sebuah nilai lebih bagi pasangan Helmi Hasan dan Dedy Wahyudi untuk melanjutkan kepemimpinan. Sehingga Efek Media massa jauh lebih besar karena mampu menjangkau khalayak sasaran dari pemberitaan yang di kemas denganprogram yang terimplementasikan.

Berdasarkan hasil penelitian mengenai Pass Political Marketing, strategi ini penyampaian pesan dilakukan melalui individu, kelompok atau organisasi yang mempunyai pengaruh. Berdasarkan penelitian, bahwa Helmi Hasan merupakan mantan pengurus Cabang HMI pada saat menjadi Mahasiswa di Universitas Bengkulu, sehingga secara emosional kedekatan antar pengurus dan Anggota dari HMI telah terbangun. Selain itu Tokoh Politik Nasional yang mendukung dan merupakan kakak kandung Helmi Hasan yaitu Zulkifli Hasan. Tidak hanya itu Dedy Wahyudi merupakan General Manajer RB TV yang memiliki pendukung dan simpatisan dari perusahaan atau TV lokal yang di pimpin. Semua pesan yang dibawa organisasi, tokoh politik, tokoh masyarakat dan tokoh agama mampu memberikan sebuah kepercayaan masyarakat untuk memilih dan menjatuhkan pilihan kepada pasangan Helmi hasan dan Dedy wahyudi.

\section{KESIMPULAN}

Berdasarkan hasil penelitian dan pembahasan maka dapat disimpulkan bahwa Marketing Politik pada Pemilihan Kepala Daerah Kota Bengkulu dengan menggunakan teori Marketing Politik dari Adnan Nursal (dalam Firmanzah,2012) yaitu Push political marketing, pull political marketing dan pass political marketing ini sebagai berikut:

1. Strategi push political marketing yang diterapkan pasangan Helmi Hasan dan Dedy Wahyudi mengenai pemasaran produk politik secara langsung kepada calon pemilih atau disebut dengan Push political marketing. Dilakukan secara langsung baik dengan mengadakan event-event khusus seperti rapat umum, pawai, kontes, seminar, konfrensi dan sebagainya. Kegiatan secara langsung telah membangun kedekatan (Proximity) dan Trust terhadap kandidat. 
2. Strategi pull political marketing, strategi yang paling banyak digunakan oleh partai dan kandidat. Penyampaian pesan dilakukan melalui media massa baik elektronik, cetak, luar ruang, mobile dan internet. Strategi ini mempunyai kelebihan dapat membombardir pesan kepada khalayak.

3. Strategi Pass Political Marketing, strategi ini penyampaian pesan dilakukan melalui individu, kelompok atau organisasi yang mempunyai pengaruh. Strategi ini mampu mendatangkan pendukung, simpatisan dari setiap organisasi atau kelompok yang di pimpin. Sehingga semakin mudah untuk menumbuhkan kepercayaan Khalayak sasaran terhadap kandidat.

\section{DAFTAR PUSTAKA}

Anwar M. Khoirul. Salviana Vina. 2006. Perilaku Partai Politik. Malang : UMM Press.

Ambong, Ibrahim. Budiardjo, Miriam. 1993. Fungsi Legislatif dalam Sistem Politik Indonesia. Jakarta:

Raja Grafindo Persada

Bungin,Burhan.2001.Metode Penelitian Kualitatif.PT.Raja Grapindo Persada.Jakarta.

Cangara, Hafidz. 2005 . Pengantar Ilmu Komunikasi, Jakarta:PT RajaGrafindo Persada

Canggara.Hafied. Pengantar Ilmu Komunikasi. PT. Raja Grafindo Persada. Jakarta. 2002.

Devito.A.Joseph.1997. Komunikasi Antar Manusia. Edisi Kelima. Professional i books. Jakarta.

Firmanzah. 2012. Marketing Politik.Jakarta:Yayasan Pustaka Obor Indonesia.

Littlejhon,Stephen w.1996. Theori of human communication. Fifth edition.

Littlejohn, Stephen W. 2001. Theories of Human Communication. USA: Wadsworth Publishing.

Moelong, Lexy J.2007.Metodologi Penelitian Kualitatif. PT. Remaja Rosdakarya. Bandung.

Morrisan.2003. Teori Komunikasi Individu hingga massa.Kencana Prenadamedia Group : Jakarta.

Nursal,Adnan.2004. Political Marketing : Strategi Memenangkan Pemilu Sebuah Pendekatan Baru Kampanye Pemilihan DPR,DPD,Presiden.Jakarta:PT.Gramedia Pustaka.

Rahman H.I. 2007. Sistem Politik Indonesia. Yogyakarta: Graha Ilmu.

Rakhmat.Jalaludin.2005.Metode Penelitian Komunikasi. PT. Remaja RosdakaryaBandung.

Rakhmat.Jalaludin. Psikologi Komunikasi. PT. Remaja Rosdakarya Bandung. 2005.

Ramlan Surbakti. Sistem pemilu dan tatanan politik demokrasi. Jakarta.2008

Ramlan surbakti, dkk (Ed.). Perekayasaan Sistem Pemilu untuk Pembangunan tata politik demokratis.

Kemitraan Jakarta.2008

Sendjaja,Sasa Djuarsa,1994,Pengantar Komunikasi,Jakarta:Universitas Terbuka.

Sugiyono. Metode Penelitian Kuantitatif, Kualitatifdan RND Alfabeta. Bandung. 2008. 